\title{
Seizure Outcome after Anterior versus Complete Corpus Callosotomy in Children: A Systematic Review with Meta-Analysis
}

\section{Controle das crises epilépticas após calosotomia anterior versus completa em crianças: uma revisão sistemática com metanálise}

\author{
Lucas Crociati Meguins ${ }^{1}$ Rodrigo Antônio Rocha da Cruz Adry ${ }^{1}$ Sebastião Carlos da Silva Júnior ${ }^{1}$ \\ Carlos Umberto Pereira ${ }^{2}$ Jean Gonçalves de Oliveira ${ }^{3}$ Dionei Freitas de Morais ${ }^{1}$ \\ Gerardo Maria de Araújo Filho ${ }^{4}$ Lúcia Helena Neves Marques ${ }^{5}$ \\ ${ }^{1}$ Neurosurgery Division, Hospital de Base, Department of Neurologic \\ Sciences, Faculdade de Medicina de São José do Rio Preto (FAMERP), \\ SP, Brazil \\ Address for correspondence Lucas Crociati Meguins, MD, MSc, Rua \\ Pedro Palotta, 101/31B, Jardim Maracanã, São José do Rio Preto, SP, \\ Brazil CEP: 15092-205 (e-mail: lucascrociati@hotmail.com).
}

${ }^{2}$ Department of Medicine, Universidade Federal de Sergipe (UFS),

Aracaju, SE, Brazil

${ }^{3}$ Division of Neurosurgery, Department of Medical Sciences, School of Medicine, Universidade Nove de Julho; Department of

Cerebrovascular and Skull Base surgery, Center of Neurology and Neurosurgery Associates, Hospital Beneficência Portuguesa de São Paulo, São Paulo, SP, Brazil

${ }^{4}$ Department of Psychiatry and Medical Psychology, FAMERP, SP, Brazil

${ }^{5}$ Neurologic Division, Hospital de Base, Department of Neurologic Sciences, FAMERP, SP, Brazil

Arq Bras Neurocir 2015;34:304-308.

\section{Abstract \\ Keywords \\ - corpus callosotomy \\ - anterior versus complete corpus callosotomy \\ - refractory epilepsy \\ - meta-analysis}

Introduction Refractory epilepsy is a debilitating and challenging condition to manage. Corpus callosotomy (CC) seems to be an effective treatment option for patients with seizures not amenable to focal resection. The aim of the present study is to compare seizure outcome of pediatric patients following anterior CC, compared with complete CC.

Method The authors performed a systematic review and meta-analysis of the English literature involving comparative studies.

Results The present investigation includes four retrospective case-controlled studies and authors perform a pooled analysis of the surgical results. Seizure outcome presented favorable results in patients who underwent complete CC (Odds Ratio, $\mathrm{M}-\mathrm{H}$, Fixed, 95\% Cl: 3.02 [1.43, 6.387], p-value: 0.005). Clinical and neurological complications occurred independently when a complete or anterior $\mathrm{CC}$ was performed. Conclusion Complete $\mathrm{CC}$ seems to be the most effective treatment option to control intractable seizure in children not amenable to focal resection. received

November 10, 2013

accepted

August 7, 2015

published online

October 20, 2015
DOI http://dx.doi.org/ 10.1055/s-0035-1564581. ISSN 0103-5355.
Copyright $\odot 2015$ by Thieme Publicações License terms Ltda, Rio de Janeiro, Brazil
(®) $\Theta \circledast$ 


\section{Resumo}

\section{Palavras-chave}

- calosotomia

- calosotomia anterior versus completa

- epilepsia refratária

- metanálise
Introdução Epilepsia refratária é uma condição debilitante e desafiadora para lidar. Calosotomia parece ser uma opção de tratamento eficaz para pacientes com convulsões não passíveis de ressecção focal. O objetivo do presente estudo é comparar o resultado de convulsões em pacientes pediátricos de acordo com calosotomia anterior e completa.

Métodos Uma revisão sistemática e metanálise da literatura médica em inglês envolvendo estudos comparativos.

Resultados Quatro casos retrospectivos foram incluídos na presente investigação e uma análise dos resultados cirúrgicos foi realizada. Convulsões decorrentes tiveram resultados favoráveis em pacientes submetidos a calosotomia complete (odds ratio, M-H, fixo, 95\% IC: 3,02 [1,43; 6,387], valor de p: 0,005). Complicações clínicas e neurológicas ocorreram independentemente de se calosotomia complete ou anterior.

Conclusão Calosotomia completa parece ser a opção de tratamento mais eficaz para controlar convulsões não rastreáveis e não passíveis de ressecção focal em crianças.

\section{Introduction}

Refractory epilepsy is a debilitating and challenging condition to manage. Corpus callosotomy (CC) seems to be an effective treatment option for patients with seizures not amenable to focal resection. The most common indication for corpus callosotomy (CC) is drop attacks (tonic or atonic), which often lead to severe physical injuries. ${ }^{1-3}$ Other possible indications for CC include West Syndrome, Lennox-Gastaut syndrome, and intractable episodes of status epilepticus or complex partial seizures with secondary generalization without any obvious foci. ${ }^{4-6} \mathrm{CC}$ may be performed in both children and adults; ${ }^{7,8}$ however, children seem to have fewer postsurgical complications than adults, apparently because of the neuronal plasticity of pediatric patients' brains. ${ }^{3}$

A well-known adverse effect of CC is the "disconnection syndrome". 9,10 Additionally, other adverse effects have been described, including language impairments and memory deficits. The complications are often transient; however, in some cases, they become permanent affecting the patient's quality of life. ${ }^{3,6,11}$ Therefore, the use of CC is restricted mainly to patients with intractable seizure. ${ }^{6}$ To spare neurological functions, some authors advocate anterior or partial CC, leaving the splenium, ${ }^{12-14}$ whereas, others consider complete or total CC to be more effective, especially in children. ${ }^{14-17}$ The present study performs a systematic review with meta-analysis of the literature that involves direct comparisons of seizure outcome among pediatric patients after anterior or complete CC. Our hypothesis is that complete CC is superior to anterior CC in producing favorable seizure outcomes, although the most relevant surgical series are likely too small to reach a strong statistical significance. A meta-analysis study improves accuracy through a pooled estimate of treatment effects.

\section{Methods}

\section{Search Strategy}

Two authors (LCM, RARCA) independently performed a comprehensive literature search of PubMed, The Cochrane Library, and Embase using the following terms, alone or in combination: "callosotomy," "corpus callosotomy," "children," "childhood," "pediatric," "anterior," "anterior twothirds," "partial," "complete," "full", and "total." The investigators identified potentially relevant articles by reviewing abstracts and then thoroughly reviewed references. Searches were restricted to English-language articles published from 2000 to 2014.

\section{Study Selection}

Inclusion criteria for the present systematic review consisted of the following: 1) articles comparing seizure outcome in pediatric patients after anterior and complete CC, 2) studies with a minimum follow-up of 3 months, 3) well-defined measure of seizure frequency reduction, either in numbers or ranges, after anterior or complete CC, 4) brief description of surgical and clinical complications following either operative procedure under investigation. Studies were excluded if seizure frequency data could not be extracted from the study population's data. Two authors (LCM, RARCA) independently reviewed studies that met inclusion criteria to determine their suitability and quality and unanimously agreed upon the studies to be included in this meta-analysis.

\section{Data Collection}

Data were collected on the following: first author's name, year of publication, country and institution of investigation, study design, sample size, type of treatment, number of patients enrolled on each type of treatment (anterior vs. complete (C), duration of follow-up, seizure-free rate, 
complication rate, and mortality. In studies where patients were listed individually, means and sums were used to represent the study in the final analysis. When possible, the outcome data were gathered according to the last followup. Not all data were available for every study.

\section{Ethical Statement}

The Ethical Committee of our institution analyzed the project for the present study and approved the performance of our investigations. The study complies with the Declaration of Helsinki.

\section{Statistical Analysis}

The software used to aid in statistical analysis were Microsoft Excel 2013 and Bio Stat 5.0 (Belém, Brazil, 2007). The authors organized the data collected from all patients in tables comparing with previous studies. Averages are expressed as the means \pm SD for parametric data and as median values for nonparametric data. Forest plot and meta-analysis of post-operative seizure outcomes were performed using the Mantel-Haenszel test (fixed effect) and odds ratio. Heterogeneity evaluation was performed using the chi-square test for contingency Tables $(2 \times 2)$. Studies were the unit of analysis. Odds ratio with 95\% CIs were used to compare pooled proportion of clinical improvement in seizure frequency between anterior and complete CC groups. A p-value $<0.01$ was considered statistically significant.

\section{Results}

\section{Eligible Articles}

-Fig. 1 summarizes the strategy utilized during the literature search for this study. After excluding non-comparative investigations, four case-controlled articles comparing seizure outcome of anterior and complete CC were included in the present meta-analysis. All studies were retrospective investigations performed in North America (-Table 1).

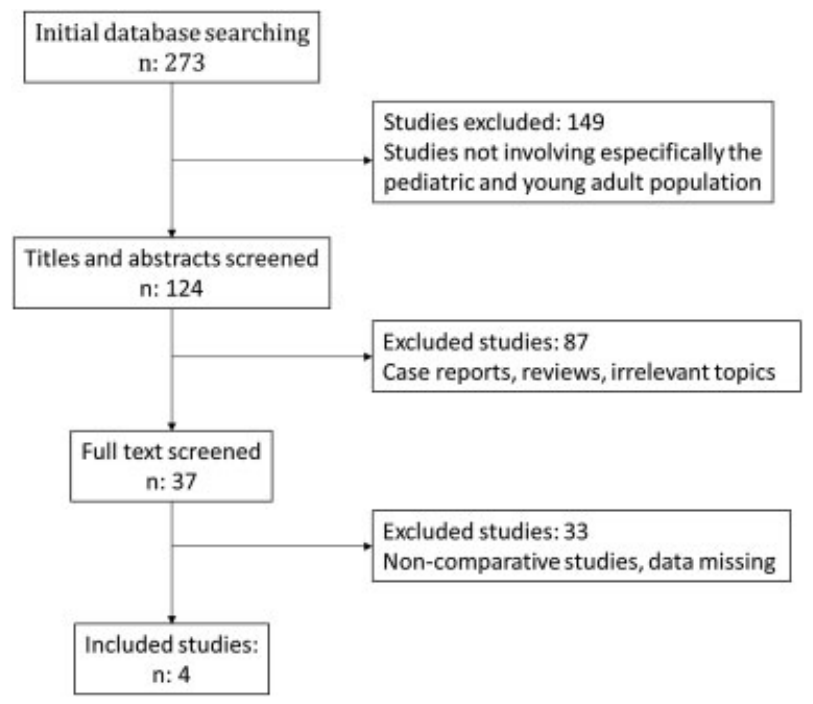

Fig. 1 Summary of the literature search strategy.

\section{Seizure Outcome}

The pooled analysis of seizure outcome after anterior and complete CC is presented in - Table $\mathbf{2}$ and - Fig. $\mathbf{2}$. A favorable surgical outcome was considered when patients achieved more than $50 \%$ of seizure reduction during follow-up or were included in one of the three groups: Engel I, II, or III. A seizure outcome was considered unfavorable when patients achieved less than $50 \%$ of seizure reduction or were classified as Engel IV during follow-up.

\section{Complications}

-Table 1 presents the rate of surgical and neurological complications from studies included in the present metaanalysis. Significant complication rates did not achieve more than $5 \%$ and disconnection syndrome was a transient neurological complication in most studies.

\section{Discussion}

Children with severe and refractory epilepsy usually suffer significant morbidity and disability. Many of them suffer cognitive decline due to the effects of frequent seizures and chronic use of anti-epileptic drugs, as well as from physical harm as a result of sudden loss of consciousness. CC is a palliative procedure for patients with medically uncontrolled seizures not amenable to focal resection. ${ }^{18}$ Van Wagenen and Herren ${ }^{19}$ first introduced it in 1940 as a therapeutic option for refractory epilepsy. Since then, many studies regarding the indication and outcome of corpus callosotomy have been published. ${ }^{20-25}$ However, there has yet to be universally accepted standard guidelines for the selection of patients for anterior versus complete CC.

In the past, anterior $\mathrm{CC}$ was believed to prevent postsurgical neurological deficits, such as the disconnection syndrome, marked by mutism, hemiataxia, and/or alexia. ${ }^{26}$ With these controversies in mind, we performed a systematic review with meta-analysis of studies directly comparing seizure outcome and evaluating complications descriptions of pediatric patients following anterior or complete CC. Our hypothesis was that complete CC was superior to anterior CC to produce favorable seizure outcomes, but most relevant surgical series were likely too small to carry strong statistical significance. Therefore, a meta-analysis study would improve precision through a pooled estimate of treatment effect.

Four studies were included in the present meta-analysis after review of the literature. The pooled analysis found that complete CC is superior to anterior CC in improving seizure outcome of pediatric patients (-Fig. 1 and - Table 2). Rahimi et al. showed a significant benefit when complete $\mathrm{CC}$ was used for secondary generalized seizures compared with anterior CC. ${ }^{14}$ Additionally, Bower et al. and Kasasbeh et al. also reported favorable outcomes of complete $\mathrm{CC}$ in controlling drop attacks and astatic seizures compared to anterior CC. ${ }^{16,17}$ Jalilian et al. reinforced that complete $\mathrm{CC}$ should be considered as the initial procedure in lower-functioning children afflicted by absence, atonic, or myoclonic seizures and that severely 
Table 1 Characteristics of studies included in the meta-analysis

\begin{tabular}{|c|c|c|c|c|c|c|}
\hline \multirow[b]{2}{*}{ Study } & \multirow[b]{2}{*}{ Year } & \multirow[b]{2}{*}{ Design } & \multicolumn{2}{|c|}{ No. of Patients } & \multirow[b]{2}{*}{ Follow-up* } & \multirow[b]{2}{*}{ Neurological Complications } \\
\hline & & & AntCC & CompCC & & \\
\hline Rahimi et al. ${ }^{14}$ & 2007 & Retro & 11 & 28 & 1.2 & $2 \%$ \\
\hline Jalilian et al. ${ }^{15}$ & 2010 & Retro & 15 & 12 & 2 & $4 \%$ \\
\hline Bower et al. ${ }^{16}$ & 2013 & Retro & 28 & 22 & 4.2 & $4 \%$ \\
\hline Kasasbeh et al. ${ }^{17}$ & 2014 & Retro & 21 & 31 & 3.2 & $5 \%$ \\
\hline
\end{tabular}

Abbreviations: AntCC, Anterior corpus callosotomy; CompCC, Complete corpus callosotomy; ${ }^{\text {, }}$ mean duration of follow-up in years; Retro, Retrospective.

Table 2 Meta-analysis of seizure outcome after AntCC and CompCC

\begin{tabular}{|l|l|l|l|l|l|l|}
\hline & \multicolumn{2}{|l|}{ AntCC } & \multicolumn{2}{l|}{ CompCC } & Odds Ratio \\
\hline Study & Success $^{\beta}$ & Total & Success $^{\beta}$ & Total & Weight & M-H, Fixed, 95\% CI \\
\hline Rahimi et al. $^{14}$ & 9 & 11 & 25 & 28 & 1.016 & $1.85[0.26,12.94]$ \\
\hline Jalilian et al. $^{15}$ & 10 & 15 & 11 & 12 & 0.719 & $5.50[0.54,55.49]$ \\
\hline Bower et al. $^{16}$ & 14 & 28 & 14 & 22 & 2.947 & $1.75[0.55,5.481]$ \\
\hline Kasasbeh et al. $^{17}$ & 12 & 21 & 28 & 31 & 1.775 & $7.00[1.60,30.48]$ \\
\hline Subtotal (95\% IC) & - & 75 & - & 93 & - & $3.02[1.43,6.387]^{*}$ \\
\hline Total (Event) & 45 & - & 78 & - & - & - \\
\hline
\end{tabular}

Abbreviations: AntCC, Anterior CC; CompCC: Complete CC; M-H, Mantel-Haenszel test.

Heterogeneity: $\mathrm{Chi}^{2}=2.29, \mathrm{p}=0.51$.

Test for overall fixed effect (M-H): ${ }^{*} p=0.005$.

$\beta$ : Success: Patients classified as Engel $\mathrm{I} / \mathrm{II} / \mathrm{III}$ or presenting $>50 \%$ seizure frequency reduction.

affected higher-functioning children may also benefit from complete CC, without significant neurological complications. $^{15}$

Statistical data from all four studies demonstrated that neurological morbidity in patients receiving complete $\mathrm{CC}$ is not greater than those receiving an anterior CC. Jalilian et al. reported suspicion of disconnection syndrome in one patient

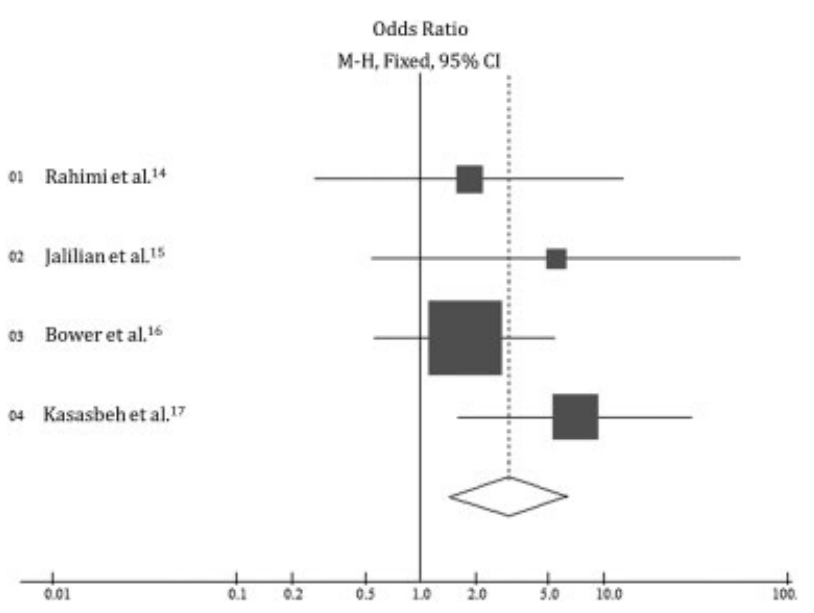

Fig. 2 Forest Plot of seizure outcome after AntCC and CompCC (M-H, Mantel-Haenszel test; AntCC, Anterior CC; CompCC, Complete CC). who received an anterior $\mathrm{CC}$ and transient mutism and weakness in four other patients after complete CC. ${ }^{15}$ Rahimi et al. also described one case of mild disconnection syndrome after complete $\mathrm{CC}$, characterized by a change in the dominant hand. ${ }^{14}$ Bower et al. and Kasasbeh et al. affirmed that clinical and neurological complications were independent of whether the CC was complete or anterior. No statistically significant difference was observed between groups with regards to length of surgery, length of hospitalization, or estimated blood loss. ${ }^{16,17}$

There are several methodological aspects in the present findings, which should be interpreted in the context of several limitations. Although an extensive systematic literature review was performed, we included only four retrospective non-randomized case-controlled studies for meta-analysis. Additionally, most studies had a small number of patients and the follow-up was relatively brief, with a mean time of 2.65 years for a pooled analysis. Nevertheless, future prospective and randomized studies with a greater number of patients are certainly necessary to confirm such observations.

\section{Conclusion}

To conclude, the management of medically refractory epilepsy is complex and challenging, and CC seems to be an appropriate option when patients have failed maximal 
medical therapy. Additionally, complete $\mathrm{CC}$ is the most effective treatment option to control intractable seizure in children not amenable to focal resection with similar neurological complications, when compared with partial CC.

\section{References}

1 Tanriverdi T, Olivier A, Poulin N, Andermann F, Dubeau F. Longterm seizure outcome after corpus callosotomy: a retrospective analysis of 95 patients. J Neurosurg 2009;110(2):332-342

2 Stigsdotter-Broman L, Olsson I, Flink R, Rydenhag B, Malmgren K. Long-term follow-up after callosotomy-a prospective, population based, observational study. Epilepsia 2014;55(2):316-321

3 Maehara T, Shimizu H. Surgical outcome of corpus callosotomy in patients with drop attacks. Epilepsia 2001;42(1):67-71

4 Suzuki Y, Baba H, Toda K, Ono T, Kawabe M, Fukuda M. Early total corpus callosotomy in a patient with cryptogenic West syndrome. Seizure 2013;22(4):320-323

5 Liang S, Zhang S, Hu X, et al. Anterior corpus callosotomy in school-aged children with Lennox-Gastaut syndrome: a prospective study. Eur J Paediatr Neurol 2014;18(6):670-676

6 Asadi-Pooya AA, Sharan A, Nei M, Sperling MR. Corpus callosotomy. Epilepsy Behav 2008;13(2):271-278

7 Park MS, Nakagawa E, Schoenberg MR, Benbadis SR, Vale FL. Outcome of corpus callosotomy in adults. Epilepsy Behav 2013; 28(2):181-184

8 Iwasaki M, Uematsu M, Nakayama T, et al. [Corpus callosotomy for children with intractable generalized epilepsy: factors for longterm seizure remission]. No To Hattatsu 2013;45(3):195-198

9 Yang PF, Lin Q, Mei Z, et al. Outcome after anterior callosal section that spares the splenium in pediatric patients with drop attacks. Epilepsy Behav 2014;36:47-52

10 Jea A, Vachhrajani S, Widjaja E, et al. Corpus callosotomy in children and the disconnection syndromes: a review. Childs Nerv Syst 2008;24(6):685-692

11 Mamelak AN, Barbaro NM, Walker JA, Laxer KD. Corpus callosotomy: a quantitative study of the extent of resection, seizure control, and neuropsychological outcome. J Neurosurg 1993; 79(5):688-695

12 Liang S, Li A, Jiang H, et al. Anterior corpus callosotomy in patients with intractable generalized epilepsy and mental retardation. Stereotact Funct Neurosurg 2010;88(4):246-252
13 Ping Z, Ji-Wen X, Gui-Song W, Hong-Yu Z, Xin T. Evaluation of efficacy and safety of anterior corpus callosotomy with keyhole in refractory seizures. Seizure 2009;18(6):417-419

14 Rahimi SY, Park YD, Witcher MR, Lee KH, Marrufo M, Lee MR. Corpus callosotomy for treatment of pediatric epilepsy in the modern era. Pediatr Neurosurg 2007;43(3):202-208

15 Jalilian L, Limbrick DD, Steger-May K, Johnston J, Powers AK, Smyth MD. Complete versus anterior two-thirds corpus callosotomy in children: analysis of outcome. J Neurosurg Pediatr 2010; 6(3):257-266

16 Bower RS, Wirrell E, Nwojo M, Wetjen NM, Marsh WR, Meyer FB. Seizure outcomes after corpus callosotomy for drop attacks. Neurosurgery 2013;73(6):993-1000

17 Kasasbeh AS, Smyth MD, Steger-May K, Jalilian L, Bertrand M, Limbrick DD. Outcomes after anterior or complete corpus callosotomy in children. Neurosurgery 2014;74(1):17-28, discussion 28

18 VanStraten AF, Ng YT. Update on the management of LennoxGastaut syndrome. Pediatr Neurol 2012;47(3):153-161

19 Van Wagenen WP, Herren RY. Surgical division of commissural pathways in the corpus callosum: relation to spread of an epileptic attack. Arch Neurol Psychiatry 1940;44(4): 740-759

20 Gates JR, Leppik IE, Yap J, Gumnit RJ. Corpus callosotomy: clinical and electroencephalographic effects. Epilepsia 1984;25(3): 308-316

21 Geoffroy G, Lassonde M, Delisle F, Décarie M. Corpus callosotomy for control of intractable epilepsy in children. Neurology 1983; 33(7):891-897

22 Purves SJ, Wada JA, Woodhurst WB, et al. Results of anterior corpus callosum section in 24 patients with medically intractable seizures. Neurology 1988;38(8):1194-1201

23 Nordgren RE, Reeves AG, Viguera AC, Roberts DW. Corpus callosotomy for intractable seizures in the pediatric age group. Arch Neurol 1991;48(4):364-372

24 McInerney J, Siegel AM, Nordgren RE, et al. Long-term seizure outcome following corpus callosotomy in children. Stereotact Funct Neurosurg 1999;73(1-4):79-83

25 Rayport M, Ferguson SM, Corrie WS. Outcomes and indications of corpus callosum section for intractable seizure control. Appl Neurophysiol 1983;46(1-4):47-51

26 Harbaugh RE, Wilson DH, Reeves AG, Gazzaniga MS. Forebrain commissurotomy for epilepsy. Review of 20 consecutive cases. Acta Neurochir (Wien) 1983;68(3-4):263-275 